\title{
Comparison Between Intravenous Nalbuphine and Lidocaine in Reducing Propofol-Induced Injection Pain During Gastroscopy: A Randomized Controlled Trial
}

\author{
Jiang Wang · Jinjuan Duan · Cuiyu Xie $\cdot$ Yongqi Yu $\cdot$ Yao Lu (D)
}

Received: July 2, 2020 / Published online: August 3, 2020

(C) The Author(s) 2020
Digital Features To view digital features for this article go to https://doi.org/10.6084/m9.figshare.12681866.

J. Wang $\cdot$ J. Duan $\cdot$ C. Xie $\cdot$ Y. Yu $\cdot$ Y. Lu ( $ه)$ Department of Anesthesiology, The First Affiliated Hospital of Anhui Medical University, Hefei, Anhui Province, People's Republic of China

e-mail: luyao-mz@163.com

J. Duan

Department of Anesthesiology, Affiliated Anqing Hospital of Anhui Medical University, Anqing, Anhui Province, People's Republic of China propofol was manually injected. The primary outcome of this study was the incidence of propofol-induced injection pain, and secondary outcomes included the severity of propofol-induced injection pain, vital signs, and adverse events, including hypotension, bradycardia $\left(<50\right.$ beats/min), hypoxemia $\left(\mathrm{SpO}_{2}<90 \%\right)$, drowsiness, physical movement, and cough.

Results: The percentages of patients with propofol injection pain were higher in group C than in group $\mathrm{N}$ and group $\mathrm{L}(64,34$, and $27 \%$, respectively, $p<0.05)$. The percentage of patients with severe pain after propofol injection was significantly higher in group $\mathrm{C}$ than in group $\mathrm{N}$ and group $\mathrm{L}(12,1$, and $0 \%$, respectively, $p<0.05)$. The doses of propofol in group $\mathrm{C}$ and group L were significantly higher than that in group N. More patients suffered hypoxemia in group $\mathrm{N}$ than in group $\mathrm{C}$ and group $\mathrm{L}$. Then, less patients got physical movement and cough in group $\mathrm{N}$.

Conclusions: Pretreatment with nalbuphine $0.1 \mathrm{mg} / \mathrm{kg}$ was effective in reducing propofol-induced injection pain and propofol consumption. Propofol combined with nalbuphine can be safely and effectively used during gastroscopy.

Trial Registration: Chinese Clinical Trial Registry; ChiCTR1900025438.

Keywords: Gastroscopy; Lidocaine; Nalbuphine; Propofol injection pain 


\section{Key Summary Points}

Why carry out this study?

Propofol is widely used in painless endoscopy anesthesia, however, the incidence of pain induced by propofol injection range from 28 to $90 \%$ in untreated patients.

Nalbuphine, a synthetic agonist and antagonist analgesic that exerts its pharmacological effects mainly through activation of $\kappa$ receptors and partial antagonism of $\mu$ receptors, has also been effectively used to treat adverse effects such as opioid-induced pruritus and myoclonus due to etomidate.

We hypothesized that pretreatment with nalbuphine can effectively reduce propofol-induced injection pain.

\section{What was learned from the study?}

This study revealed that pretreatment with nalbuphine $0.1 \mathrm{mg} / \mathrm{kg}$ effectively decreased propofol-induced injection pain and propofol consumption during gastroscopy.

Pretreatment with nalbuphine $0.1 \mathrm{mg} / \mathrm{kg}$ can reduce propofol-induced injection pain.

The combination of propofol and nalbuphine is effective and safe and did not cause any adverse effects in painless gastroscopy.

\section{INTRODUCTION}

Propofol is often used in painless endoscopy anesthesia because of its advantages, including its rapid onset and its association with early recovery. However, the incidence of pain induced by propofol injection range from 28 to $90 \%$ in untreated patients $[1,2]$. To reduce propofol-induced injection pain, mediumchain and long-chain triglycerides have been used. In addition, many pharmacological interventions, such as dexmedetomidine [3] and lidocaine [4], have been used to prevent pain associated with propofol. However, the addition of lidocaine may disrupt the stability of propofol emulsions and may cause pulmonary embolism [5]. Although pretreatment with dexmedetomidine can reduce propofolinduced injection pain safely and effectively, its lengthy onset is not convenient for clinical use.

Nalbuphine has also been effectively used to treat adverse effects such as opioid-induced pruritus [6] and myoclonus due to etomidate [7]. In addition, pretreatment with opioids can prevent propofol-induced pain through central or peripheral effects $[8,9]$. Data on the influence of nalbuphine on pain caused by propofol have not been published. Therefore, the principal objective of the current study was to investigate the efficacy of nalbuphine $0.1 \mathrm{mg} / \mathrm{kg}$ and lidocaine $0.5 \mathrm{mg} / \mathrm{kg}$ compared to placebo in reducing propofol-induced pain during gastroscopy.

\section{METHODS}

\section{Study Protocol}

The study protocol was conducted at the First Affiliated Hospital of Anhui Medical University from September 1 to 30, 2019, in accordance with the Declaration of Helsinki. The study was approved by the hospital's research ethics committee (The First Affiliated Hospital of Anhui Medical University Ethics Committee, PJ 2019-12-19) and was registered in the Chinese Clinical Trial Registry (ChiCTR1900025438, Principal investigator: Yao $\mathrm{Lu}$, Date of registration: 2019-8-26). Written informed consent was obtained from all participants in this study.

A total of 330 patients who were American Society of Anesthesiologists (ASA) I-II, aged between 18 and 60, and planned to undergo gastroscopy were recruited for this research. Participants with no recent history of hepatic or renal insufficiency, a severe allergic or hypersensitivity reaction to the study drugs, cardiovascular or neurological disease, pregnant 
women, or a difficult airway, obesity, and patients taking opioids were excluded. We used a random number table to randomly divide the 300 patients into three groups of 100 patients each. Group N was pre-treated with nalbuphine (Yichang Humanwell Pharmaceutical Co., China) $0.1 \mathrm{mg} / \mathrm{kg}$; group L was pre-treated with lidocaine $0.5 \mathrm{mg} / \mathrm{kg}$; and group $\mathrm{C}$ was pre-treated with an equivalent volume of normal saline. The randomized grouping results were sealed in opaque envelopes until the pretreatment drug was prepared. Neither the patients nor the participating anesthesiologists were blinded to the randomized grouping results. The pre-treating agents were prepared in a $10-\mathrm{ml}$ syringe with either $10 \mathrm{ml}$ of normal saline, $0.1 \mathrm{mg} / \mathrm{kg}$ of nalbuphine, or $0.5 \mathrm{mg} / \mathrm{kg}$ of lidocaine (diluted with normal saline to $10 \mathrm{ml}$ ) by an anesthesiologist who did not participate in anesthesia induction.

\section{Standard Anesthesia Protocol}

On arrival to the gastroendoscopic room, routine monitoring, including non-invasive blood pressure, electrocardiography, and peripheral capillary oxygen saturation $\left(\mathrm{SpO}_{2}\right)$ monitoring, was performed. In addition, we placed an $18 \mathrm{G}$ intravenous catheter in the largest vein on the back of the patients' hands, and a $0.9 \%$ sodium chloride infusion was started. The patients were oxygenated and the pre-treating agents were infused before the administration of propofol. After 1 min of pre-treating drug administration, we manually injected $0.5 \mathrm{mg} / \mathrm{kg}$ propofol over $15 \mathrm{~s}$.

\section{Outcome Measures}

Our primary outcome of this study was the incidence of propofol-induced injection pain. Secondary outcomes included the severity of propofol-induced injection pain, vital signs, and adverse events, including hypotension, bradycardia $(<50$ beats/min), hypoxemia $\left(\mathrm{SpO}_{2}<90 \%\right)$, drowsiness, physical movement, and cough. An anesthesiologist who was blinded to the intervention assessed the pain according to a four-point pain scale. From the injection of propofol to sedation, we asked the patient whether they had any discomfort. The severity of propofol-injection pain was evaluated using the following four-point pain response scale: level 0 , no pain; level 1 , mild pain but no physical activity; level 2 , moderate pain, pain when asked by the anesthesiologist, or complaint of pain during the injection accompanied by physical activity; and level 3, severe pain, a response accompanied by a facial expression of pain, or a strong vocal response, arm withdrawal, or tears [9]. After assessing the pain response, we injected an additional amount of propofol to complete the gastroscopy.

\section{Statistical Analyses}

In the published data, the incidence of pain due to propofol injection is $46 \%$ in untreated patients [10]. We hypothesized a 50\% reduction in the incidence of pain after propofol administration based on an alpha of 0.05 and a power of $80 \%$. Under these assumptions, 69 patients were included in each group to detect a significant difference. Considering potential loss to follow-up, we increased the sample size of each group to 100 patients.

All data are reported as number (percentages) or the mean \pm standard deviation. We used analyses of variance to compare the continuous data of patients among the three groups. Chisquared tests were used to analyze the incidence and severity of pain induced by propofol, ASA class, and gender. We used SPSS 13.0 statistical software to analyze all data; $p$ values $<0.05$ were defined as statistically significant.

\section{RESULTS}

A total of 330 patients were recruited for this study. However, 30 patients were excluded due to failure to meet the inclusion criteria or patient refusal (Fig. 1). The demographic data and ASA status were compared among the three groups. We found no statistically significant differences in the demographic data among three groups. The doses of propofol in group C 


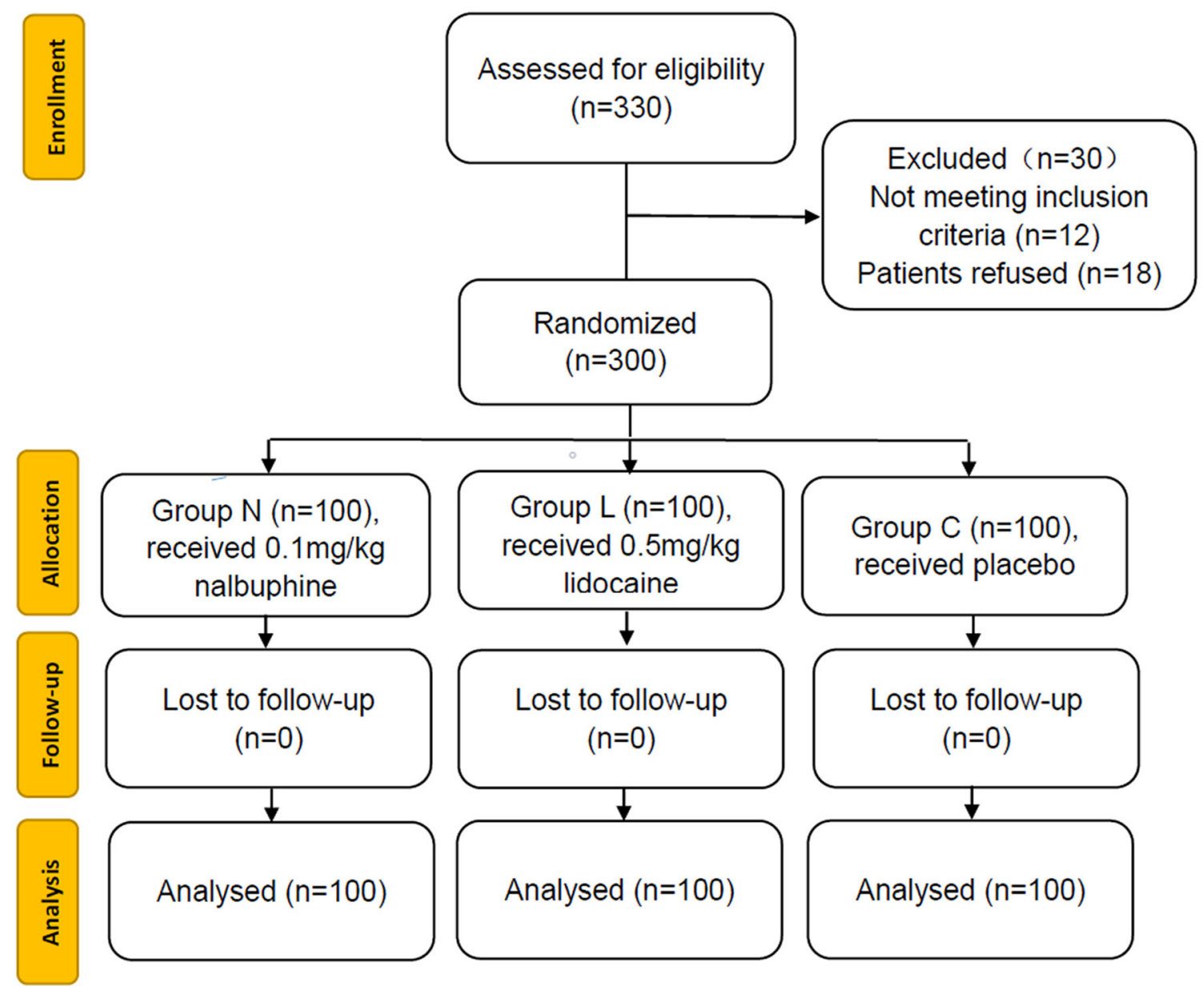

Fig. 1 CONSORT flow of clinical procedures for the study. Group C: placebo; group L: lidocaine $0.5 \mathrm{mg} / \mathrm{kg}$; group N: nalbuphine $0.1 \mathrm{mg} / \mathrm{kg}$

and group L were significantly higher than that in group $\mathrm{N}$ (Table 1). The incidence of propofolinduced injection pain was higher in group $\mathrm{C}$ than in group $\mathrm{N}$ and group L. The percentage of patients with mild pain after propofol injection significantly decreased in group $\mathrm{N}$ compared with the percentages in group $\mathrm{C}$ and group $\mathrm{L}$. No statistically significant difference between the percentages of patients with moderate pain of these groups was evident. The percentage of patients with severe pain following propofol injection significantly increased in group $\mathrm{C}$ compared with the percentages in group $\mathrm{N}$ and group L (Table 2).

The proportion of patients with hypoxemia significantly increased in group $\mathrm{N}$ compared with the proportions in group $\mathrm{C}$ and group $\mathrm{L}$. In addition, the proportion of patients who required a chin lift significantly increased in group $\mathrm{N}$ compared with those in group $\mathrm{C}$ and group L. The proportion of patients with physical movement and cough significantly decreased in group $\mathrm{N}$ compared with those in group $\mathrm{C}$ and group L (Table 3 ).

There were no differences in the systolic blood pressure (SBP) or diastolic blood pressure (DBP) at any time point among the three groups. At $\mathrm{T}_{1}$, the heart rate was significantly higher in group $\mathrm{C}$ than in group $\mathrm{N}$ and group $\mathrm{L}$. At $\mathrm{T}_{2}$, the heart rate was significantly higher in group $\mathrm{C}$ than in group $\mathrm{N}$ and group $\mathrm{L}$, and $\mathrm{SpO}_{2}$ decreased in group $\mathrm{N}$ compared with that in group $\mathrm{C}$ and group L (Fig. 2). 
Table 1 Demographic data of the patients and propofol dose in three groups

\begin{tabular}{lllll}
\hline & $\begin{array}{l}\text { Group N } \\
(\boldsymbol{n}=\mathbf{1 0 0})\end{array}$ & $\begin{array}{l}\text { Group L } \\
(\boldsymbol{n}=\mathbf{1 0 0})\end{array}$ & $\begin{array}{l}\text { Group C } \\
(\boldsymbol{n}=\mathbf{1 0 0})\end{array}$ & $\boldsymbol{p}$ value \\
\hline Gender (F/M) & $66 / 34$ & $54 / 46$ & $55 / 45$ & 0.161 \\
Age & $46 \pm 8$ & $45 \pm 11$ & $46 \pm 10$ & 0.759 \\
Height & $163 \pm 6$ & $164 \pm 8$ & $165 \pm 8$ & 0.633 \\
Weight & $59 \pm 9$ & $61 \pm 11$ & $60 \pm 10$ & 0.776 \\
ASA score (I/II) & $86 / 14$ & $87 / 13$ & $91 \pm 9$ & 0.515 \\
Mallampati (I/II) & $12 / 88$ & $10 / 90$ & $8 / 92$ & 0.641 \\
Propofol dose & $136 \pm 20$ & $158 \pm 34^{\mathrm{a}}$ & $160 \pm 29^{\mathrm{a}}$ & 0.000 \\
\hline
\end{tabular}

Group $\mathrm{C}=$ placebo; group $\mathrm{L}=$ lidocaine $0.5 \mathrm{mg} / \mathrm{kg}$; group $\mathrm{N}=$ nalbuphine $0.1 \mathrm{mg} / \mathrm{kg}$

$A S A$ American Society of Anesthesiologists

${ }^{a}$ Multiple comparison on dose of propofol: $p<0.05$ vs. group $\mathrm{N}$

Table 2 Incidence of injection pain due to propofol in different groups

\begin{tabular}{llll}
\hline & Group & \\
\cline { 2 - 4 } & Group N $(\boldsymbol{n}=\mathbf{1 0 0})$ & Group L $(\boldsymbol{n}=\mathbf{1 0 0})$ & Group C $(\boldsymbol{n}=\mathbf{1 0 0})$ \\
\hline Patients with pain [no. (\%)] & $27(27 \%)$ & $34(34 \%)$ & $64(64 \%)$ \\
Severity of pain [no. (\%)] & & & \\
0 & $73(73 \%)^{\mathrm{a}}$ & $66(66 \%)^{\mathrm{a}}$ & $36(36 \%)$ \\
1 & $19(19 \%)^{\mathrm{a}}$ & $25(25 \%)$ & $37(37 \%)$ \\
2 & $7(7 \%)$ & $9(9 \%)$ & $15(15 \%)$ \\
3 & $1(1 \%)^{\mathrm{a}}$ & $0(0 \%)^{\mathrm{a}}$ & $12(12 \%)$ \\
\hline
\end{tabular}

Group $\mathrm{C}=$ placebo; group $\mathrm{L}=$ lidocaine $0.5 \mathrm{mg} / \mathrm{kg}$; group $\mathrm{N}=$ nalbuphine $0.1 \mathrm{mg} / \mathrm{kg}$

${ }^{a}$ Multiple comparison on incidence of propofol injection pain: $p<0.05$ vs. group $\mathrm{C}$

\section{DISCUSSION}

This study revealed that pretreatment with nalbuphine $0.1 \mathrm{mg} / \mathrm{kg}$ effectively decreased propofol-induced injection pain compared to placebo. In group $\mathrm{C}$, the incidence of propofolinduced injection pain was $64 \%$, which is consistent with the incidence in a previous study [11].

Propofol has become a popular sedativehypnotic agent in endoscopy. However, pain associated with propofol is a common adverse event [12]. The exact mechanism of propofol- induced injection pain is unknown. Many factors, including the size of the vein [13, 14], injection site [15] and injection speed [13], and concentration of propofol in the aqueous phase [16], seem to contribute to the incidence of injection pain. Various strategies have been applied to reduce the incidence of pain induced by propofol, such as diluting the propofol injection solution, embedding larger veins, and administering lidocaine [2]. Other drugs, such as nonsteroidal anti-inflammatory drugs [17], ketamine, and magnesium sulfate, have been used to relieve pain associated with propofol. 
Table 3 Comparison of adverse events between the three groups

\begin{tabular}{llll}
\hline & $\begin{array}{l}\text { Group N } \\
(\boldsymbol{n}=\mathbf{1 0 0})\end{array}$ & $\begin{array}{l}\text { Group L } \\
(\boldsymbol{n}=\mathbf{1 0 0})\end{array}$ & $\begin{array}{l}\text { Group C } \\
(\boldsymbol{n}=\mathbf{1 0 0})\end{array}$ \\
\hline Hypotension & 44 & 32 & 31 \\
Bradycardia $(<50$ beats/min) & 15 & 6 & 8 \\
Hypoxemia $\left(\mathrm{SpO}_{2}<90 \%\right)$ & 18 & $2^{\mathrm{a}}$ & $3^{\mathrm{a}}$ \\
Chin lift & 10 & $2^{\mathrm{a}}$ & $3^{\mathrm{a}}$ \\
Drowsiness & 45 & 36 & 46 \\
Physical movement and cough & 2 & $18^{\mathrm{a}}$ & $25^{\mathrm{a}}$ \\
\hline
\end{tabular}

Group $\mathrm{C}=$ placebo; group $\mathrm{L}=$ lidocaine $0.5 \mathrm{mg} / \mathrm{kg}$; group $\mathrm{N}=$ nalbuphine $0.1 \mathrm{mg} / \mathrm{kg}$

a Multiple comparison on adverse events: $p<0.05$ vs. group $\mathrm{N}$
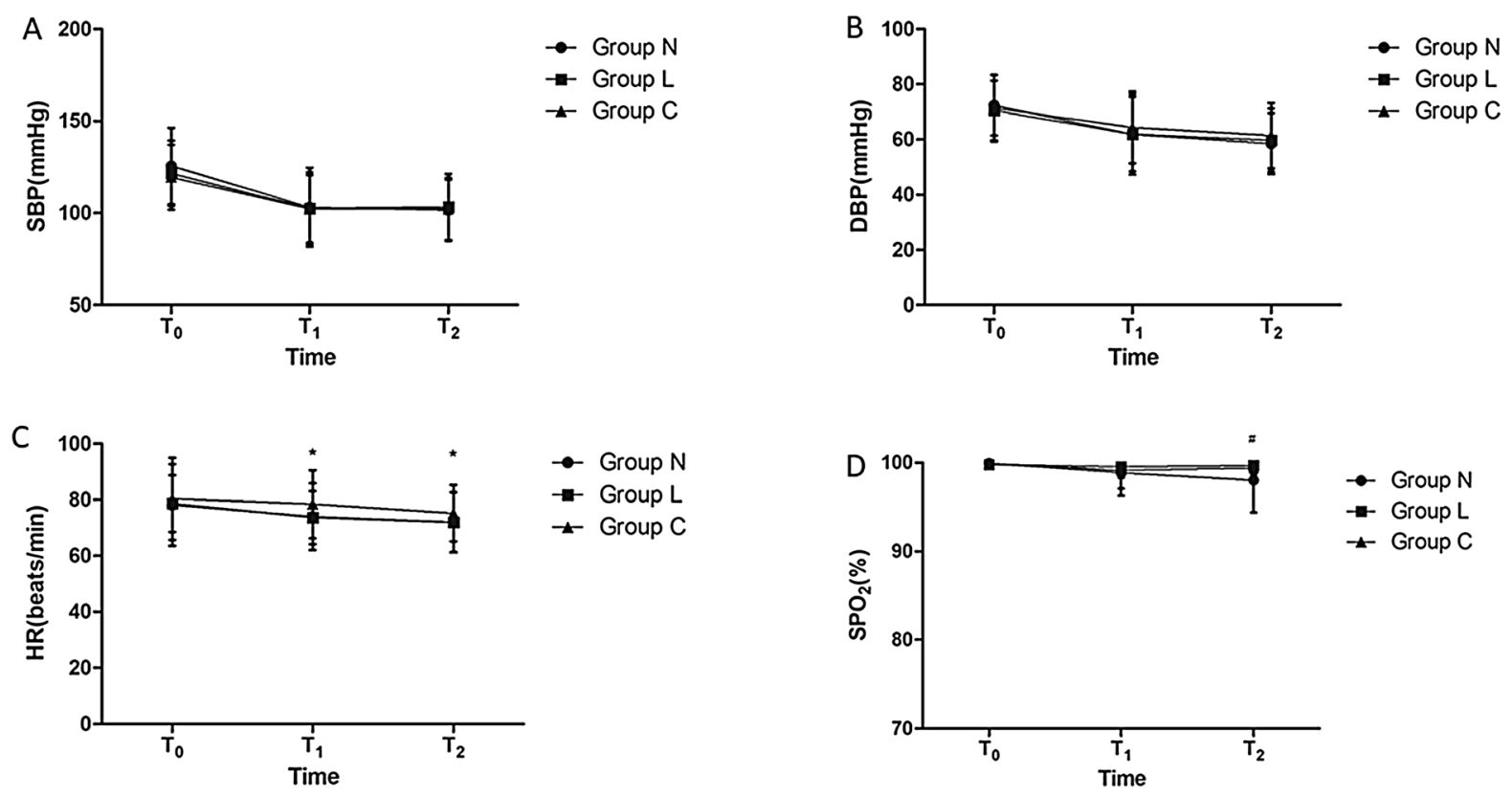

Fig. 2 Changes in the vital signs in the three groups. a Systolic blood pressure (SBP, $\mathrm{mmHg}$ ); $\mathbf{b}$ diastolic blood pressure (DBP, $\mathrm{mmHg}$ ); $\mathbf{c}$ heart rate (HR, beats/min); d peripheral capillary oxygen saturation $\left(\mathrm{SpO}_{2}, \%\right)$. Group C: placebo; group L: lidocaine $0.5 \mathrm{mg} / \mathrm{kg}$; group $\mathrm{N}$ : nalbuphine $0.1 \mathrm{mg} / \mathrm{kg}$; $\mathrm{T}_{0}$ : time before administration of

Lidocaine is a common local anesthetic, which reversibly blocks peripheral pathways by acting on excitable membranes. In a previous study, premedication with lidocaine $0.5 \mathrm{mg} / \mathrm{kg}$ before propofol injection reduced the incidence of propofol-induced injection pain [18]. In our

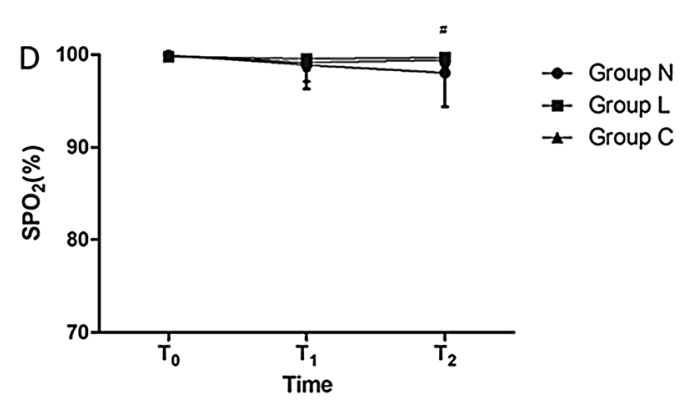

pretreatment drug or normal saline injection; $T_{1}$ : at the beginning of the surgery; $\mathrm{T}_{2}$ : at the end of surgery. ${ }^{*} P<0.05$ compared with group $\mathrm{C}$; ${ }^{\#} P<0.05$ compared with group $\mathrm{N}$

study, the incidence of propofol injection pain was $34 \%$ in group L, which is consistent with the incidence in a previous study [18].

Opioids, including remifentanil and sufentanil, have been used to alleviate propofol injection pain [19]. Roehm et al. [20] found that 
lidocaine $40 \mathrm{mg}$ was as effective as a continuous intravenous remifentanil infusion $(0.25 \mu \mathrm{g} / \mathrm{kg} /$ min) in the prevention of propofol-induced injection pain. Honarmand et al. [19] showed that sufentanil $10 \mu \mathrm{g}$ significantly attenuated the incidence of pain without significant changes in cardiovascular variables. Opioids act peripherally and centrally [21]. Their prevention of pain due to propofol injection has been attributed to their interaction with peripheral $\mu$ opioid receptors [9]. In addition, other studies have suggested that the prevention of propofolinduced pain by opioids may be mediated by central opioid receptors [11]. Nalbuphine is a synthetic agonist and antagonist analgesic that exerts its pharmacological effects mainly through activation of $\kappa$ receptors and partial antagonism of $\mu$ receptors. This study showed that pretreatment with nalbuphine $0.1 \mathrm{mg} / \mathrm{kg}$ effectively reduced propofol-induced injection pain compared with placebo. A previous study suggested that intravenous administration of opioids with tourniquet block before propofol injection was unable to relieve propofol injection pain [11]. Therefore, we hypothesized that nalbuphine alleviates pain with propofol injection mainly through a central pathway.

Tachycardia is often used as a clinical indicator of pain. At $T_{1}$ and $T_{2}$, the heart rate was significant higher in group $\mathrm{C}$ than in group $\mathrm{N}$ and group L, which indicates that lidocaine and nalbuphine were able to reduce propofol-induced injection pain. Nalbuphine can reduce visceral pain by acting on $\kappa$ receptors [22], and the dose of propofol was reduced in group N. In addition, the incidence of physical activity and cough decreased. The percent of hypoxemia was significantly higher in patients with nalbuphine $0.1 \mathrm{mg} / \mathrm{kg}$. A possible reason for this is that nalbuphine $0.1 \mathrm{mg} / \mathrm{kg}$ with use of sedative can cause respiratory depression. Although more patients had hypoxemia in group $\mathrm{N}$, most of them demonstrated relief with just a chin lift.

A limitation of our study is that we did not investigate the effects of other doses of nalbuphine on the incidence of propofol-induced injection pain. Additionally, this study was only conducted at a single center. In the future, we will coordinate with different hospitals to evaluate the effects of nalbuphine on the frequency of propofol-induced pain.

\section{CONCLUSIONS}

In conclusion, this study clearly indicated that the combination of propofol and nalbuphine is effective and safe and did not cause any adverse effects in painless gastroscopy. Pretreatment with nalbuphine $0.1 \mathrm{mg} / \mathrm{kg}$ can reduce propofol-induced injection pain. In addition, the dose of propofol was significantly decreased.

\section{ACKNOWLEDGEMENTS}

We thank the participants of the study.

Funding. This work and the journal's Rapid Service Fee were funded by the National Natural Science Foundation of China (No. 81770295) and the Key Project of Excellent Youth in Higher Education Institution of Anhui Province (gxyqZD2018028).

Authorship. All named authors meet the International Committee of Medical Journal Editors (ICMJE) criteria for authorship for this article, take responsibility for the integrity of the work as a whole, and have given their approval for this version to be published.

Authorship Contributions. All authors contributed to data analysis, drafting, or revising the article, gave final approval of the version to be published, and agree to be accountable for all aspects of the work. Jiang Wang and Jinjuan Duan contributed equally to this work.

Disclosures. Jiang Wang, Jinjuan Duan, Cuiyu Xie, Yongqi Yu and Yao Lu have nothing to disclose.

Compliance with Ethics Guidelines. The study protocol was conducted at the First Affiliated Hospital of Anhui Medical University from September 1 to 30, 2019, in accordance with the Declaration of Helsinki. The study was approved by the hospital's research ethics 
committee (The First Affiliated Hospital of Anhui Medical University Ethics Committee, PJ 2019-12-19) and was registered in the Chinese Clinical Trial Registry (ChiCTR1900025438, Principal investigator: Yao Lu, Date of registration: 2019-8-26). Written informed consent was obtained from all participants in this study.

Data Availability. The datasets generated during and/or analyzed during the current study are available from the corresponding author on reasonable request.

Open Access. This article is licensed under a Creative Commons Attribution-NonCommercial 4.0 International License, which permits any non-commercial use, sharing, adaptation, distribution and reproduction in any medium or format, as long as you give appropriate credit to the original author(s) and the source, provide a link to the Creative Commons licence, and indicate if changes were made. The images or other third party material in this article are included in the article's Creative Commons licence, unless indicated otherwise in a credit line to the material. If material is not included in the article's Creative Commons licence and your intended use is not permitted by statutory regulation or exceeds the permitted use, you will need to obtain permission directly from the copyright holder. To view a copy of this licence, visit http://creativecommons.org/licenses/by$\mathrm{nc} / 4.0 /$.

\section{REFERENCES}

1. Mangar D, Holak EJ. Tourniquet at $50 \mathrm{mmHg}$ followed by intravenous lidocaine diminishes hand pain associated with propofol injection. Anesth Analg. 1992;74(2):250-2. https://doi.org/10.1213/ 00000539-199202000-00014.

2. Picard P, Tramer MR. Prevention of pain on injection with propofol: a quantitative systematic review. Anesth Analg. 2000;90(4):963-9. https:// doi.org/10.1097/00000539-200004000-00035.

3. Li X, Chen CJ, Tan F, et al. Effect of dexmedetomidine for attenuation of propofol injection pain in electroconvulsive therapy: a randomized controlled study. J Anesth. 2018;32(1):70-6. https://doi.org/ 10.1007/s00540-017-2430-3.

4. Euasobhon P, Dej-Arkom S, Siriussawakul A, et al. Lidocaine for reducing propofol-induced pain on induction of anaesthesia in adults. Cochrane Database Syst Rev. 2016;2:CD007874. https://doi. org/10.1002/14651858.CD007874.pub2.

5. Davies AF, Vadodaria B, Hopwood B, Dexter T, Conn D. Efficacy of microfiltration in decreasing propofol-induced pain. Anaesthesia. 2002;57(6): 557-61. https://doi.org/10.1046/j.1365-2044.2002. 02602.x.

6. Jannuzzi RG. Nalbuphine for treatment of opioidinduced pruritus: a systematic review of literature. Clin J Pain. 2016;32(1):87-93. https://doi.org/10. 1097/AJP.0000000000000211.

7. Bisht M, Pokhriyal AS, Khurana G, Sharma JP. Effect of fentanyl and nalbuphine for prevention of etomidate-induced myoclonus. Anesth Essays Res. 2019;13(1):119-25. https://doi.org/10.4103/aer. AER_188_18.

8. Lee JR, Jung CW, Lee YH. Reduction of pain during induction with target-controlled propofol and remifentanil. $\mathrm{Br} \mathrm{J}$ Anaesth. 2007;99(6):876-80. https://doi.org/10.1093/bja/aem293.

9. Kwak K, Kim J, Park S, et al. Reduction of pain on injection of propofol: combination of pretreatment of remifentanil and premixture of lidocaine with propofol. Eur J Anaesthesiol. 2007;24(9):746-50. https://doi.org/10.1017/S026502150600233X.

10. Galgon RE, Strube P, Heier J, Groth J, Wang S, Schroeder KM. Magnesium sulfate with lidocaine for preventing propofol injection pain: a randomized, double-blind, placebo-controlled trial. J Anesth. 2015;29(2):206-11. https://doi.org/10. 1007/s00540-014-1892-9.

11. Wrench IJ, Girling KJ, Hobbs GJ. Alfentanil-mediated analgesia during propofol injection: no evidence for a peripheral action. $\mathrm{Br} \mathrm{J}$ Anaesth. 1996;77(2):162-4. https://doi.org/10.1093/bja/77. 2.162 .

12. Salman AE, Salman MA, Saricaoglu F, Akinci SB, Aypar U. Pain on injection of propofol: a comparison of methylene blue and lidocaine. J Clin Anesth. 2011;23(4):270-4. https://doi.org/10.1016/ j.jclinane.2010.09.008.

13. Scott RP, Saunders DA, Norman J. Propofol: clinical strategies for preventing the pain of injection. Anaesthesia. 1988;43(6):492-4. https://doi.org/10. 1111/j.1365-2044.1988.tb06641.x. 
14. Briggs LP, Clarke RS, Dundee JW, Moore J, Bahar M, Wright PJ. Use of di-isopropyl phenol as main agent for short procedures. Br J Anaesth. 1981;53(11): 1197-202.

15. McCulloch MJ, Lees NW. Assessment and modification of pain on induction with propofol (Diprivan). Anaesthesia. 1985;40(11):1117-20. https:// doi.org/10.1111/j.1365-2044.1985.tb10615.x.

16. Klement W, Arndt JO. Pain on iv injection of some anaesthetic agents is evoked by the unphysiological osmolality or $\mathrm{pH}$ of their formulations. $\mathrm{Br} \mathrm{J}$ Anaesth. 1991;66(2):189-95. https://doi.org/10. 1093/bja/66.2.189.

17. El-Radaideh KM. Effect of pretreatment with lidocaine, intravenous paracetamol and lidocaine-fentanyl on propofol injection pain. Comparative study. Rev Bras Anestesiol. 2007;57(1):32-8. https:// doi.org/10.1590/s0034-70942007000100004.

18. Turan A, Memis D, Kaya G, Karamanlioglu B. The prevention of pain from injection of propofol by dexmedetomidine and comparison with lidocaine.
Can J Anaesth. 2005;52(5):548-9. https://doi.org/ $10.1007 / \mathrm{BF} 03016541$.

19. Honarmand A, Safavi M. Prevention of propofolinduced injection pain by sufentanil: a placebocontrolled comparison with remifentanil. Clin Drug Investig. 2008;28(1):27-35. https://doi.org/ 10.2165/00044011-200828010-00004.

20. Roehm KD, Piper SN, Maleck WH, Boldt J. Prevention of propofol-induced injection pain by remifentanil: a placebo-controlled comparison with lidocaine. Anaesthesia. 2003;58(2):165-70. https:// doi.org/10.1046/j.1365-2044.2003.02964_2.x.

21. Tan $\mathrm{CH}$, Onsiong MK. Pain on injection of propofol. Anaesthesia. 1998;53(5):468-76. https://doi. org/10.1046/j.1365-2044.1998.00405.x.

22. Schmauss C, Doherty C, Yaksh TL. The analgetic effects of an intrathecally administered partial opiate agonist, nalbuphine hydrochloride. Eur J Pharmacol. 1982;86(1):1-7. https://doi.org/10.1016/ 0014-2999(82)90389-2. 